\title{
Physical Therapy and Manipulation under Anesthesia for Patients with Frozen Shoulder
}

\author{
Putu Feryawan Meregawa' ${ }^{1}$, John Nolan ${ }^{2}$ \\ ${ }^{1}$ Departement of Orthopaedic and Traumatology, Medical Faculty, Udayana University-Sanglah General \\ Hospital Denpasar, Indonesia, ${ }^{2}$ Faculty of Medicine, Udayana University, Denpasar \\ Corresponding Author: Putu Feryawan Meregawa
}

DOI: https://doi.org/10.52403/ijshr.20220118

\begin{abstract}
Frozen Shoulder (FS) has been a common disease that causes notable morbidity. Conservative treatments starting from oral medication, physical therapy, exercise, steroid injection, and hydrodilatation can be chosen before surgical procedure. Recently, there are many arguments regarding the manipulation under anesthesia (MUA) procedure whether it is good or bad compared to physical therapy. This paper is done by reviewing and searching journals with "frozen shoulder", "physical therapy", "manipulation under anesthesia", and "conservative" on the search engines. From 47 journals that were reviewed, 45 were found composed as references for this review. There is no exact consensus from few pieces of literature to define which FS patients will benefit the most following the MUA procedure. Physical therapy or home exercise is still the first-line treatment for FS. Most of the cases showed that this first line of treatment is capable of resolving FS. physical therapy has its place in every phase of the FS, starting from the freezing until the thawing phase. Physical therapy remains the key and core choice of treatment in treating the patient with FS. It seems that physical therapy still the most important treatment to be applied as most of the studies reported satisfaction alongside the combination of other conservative treatments.
\end{abstract}

Keywords: frozen shoulder, physical therapy, manipulation under anesthesia, conservative

\section{INTRODUCTION}

Frozen Shoulder first described as a "periarthritis scapulohumeral" which has been a common disease that causes notable morbidity. ${ }^{1}$ In 1934, Codman described usual features following the terminology of frozen shoulder which contains a slow onset of pain felt near the insertion of the deltoid muscle, inability to sleep on the affected side, and limitation in both active and passive elevation and external rotation, whereas there are no radiological examinations abnormalities can be noted. ${ }^{2,3}$ Frozen shoulder is estimated to affect $2 \%$ of all population. ${ }^{4}$ Frozen shoulder has a cumulative incidence of 2.4 per 1000 person-years. ${ }^{5}$ Frozen shoulder is frequently found in patients with increasing age between 40 and 60, a small number of cases were found in the age below 40 and above 70 unless of secondary traumatic frozen shoulder. In general, this condition affects women somewhat more than men. ${ }^{6}$

There are several symptoms that may occur in frozen shoulder, many patients complained of having a painful restriction of shoulder motion because of several factors such as pain inhibition, weakness from rotator cuff tears, or neurological deficits. These can occur with no underlying causes. ${ }^{3}$ There are two classifications for frozen shoulder, the primary or secondary. ${ }^{7}$ Frozen shoulder which is associated with other comorbidities such as diabetes mellitus, thyroid diseases, and Parkinson's disease is called primary idiopathic frozen shoulder. ${ }^{8-}$ 10 On the other hand, secondary frozen shoulder or adhesive capsulitis is associated with shoulder injuries or immobilization 
including rotator cuff tendon tear, subacromial impingement, biceps tenosynovitis, and calcific tendonitis. The pain from the shoulder leads to the restrictive movement of the shoulder resulting in the development of a frozen shoulder. ${ }^{11}$

There are several modalities of treatment that can be chosen in treating patients with frozen shoulder. Conservative treatments starting from oral medication, physical therapy, exercise, steroid injection, and hydrodilatation can be chosen before jumping into the surgical procedures. ${ }^{12}$ Manipulation under anesthesia (MUA) is also a choice of treatment which might be chosen by tearing of the thickened inflamed capsule and contracted ligaments. ${ }^{13}$

Recently, there are many arguments regarding the MUA procedure whether it is good or bad compared to physical therapy. By using the MUA procedure, a tight frozen shoulder joint capsule is stretched and forced to be torn with manipulation. ${ }^{14}$ Some groups believe that it is a time-efficient procedure and relatively easy to perform. MUA also showed significant quick restoration of the ROM of the shoulder joint and diminishes the symptoms of frozen shoulder. On the other hand, opponents argue that the process of manipulation cannot be seen which may worsen the capsule condition or damage other structures, and prefer enhancing the physical exercises. Some serious complications of MUA are including humeral shaft fracture and rotator cuff injury. ${ }^{15,16}$ Due to the argumentation, MUA is considered a controversial procedure for frozen shoulder. The timing to start the MUA procedure in the frozen shoulder is also still a discussion among the clinicians whereas some prefer to keep sticking in the physical exercise. Moreover, the indication for MUA in the frozen shoulder remains unclear. ${ }^{17}$ In this review, the author will discuss the MUA procedure in the frozen shoulder to gain more insight and discussing the importance of physical therapy compared to MUA.

\section{DISCUSSION}

\section{Overview of Frozen Shoulder}

Frozen shoulder or also known as adhesive capsulitis is described as "a condition of uncertain etiology, characterized by significant restriction of both active and passive shoulder motion that occurs in the absence of a known intrinsic shoulder disorder". ${ }^{18}$ Insidious shoulder stiffness, severe pain that usually worsens at night, and near-complete loss of passive and active external rotation of the shoulder are typical symptoms in the patients with frozen shoulder. One of the main problems is the absence of notable findings in the patient's history, clinical examination, or radiographic evaluation to explain the loss of motion or pain. ${ }^{19}$

As explained before, the frozen shoulder can be divided into the primary idiopathic and secondary frozen shoulder. ${ }^{7}$ There are three stages of a progressing frozen shoulder, starting from freezing (painful), frozen (adhesive), and thawing phases. The freezing stage occurs and lasts around 2-9 months which is followed by several symptoms such as, gradual onset of diffuse, severe shoulder pain that characteristically worsens at night. In the frozen stage, some immobility will appear as the pain begin to diminish. The typical signs of this stage are progressive loss of glenohumeral flexion, abduction, internal rotation, and external rotation which can last around 4-12 months. The patient may finish the condition in the thawing stage, in this stage the patients experience a better condition toward the return of range of motion which needs 5-26 months to recover completely. ${ }^{20-22}$

The etiology of primary adhesive capsulitis is still unexplored. It is usually associated with some systemic conditions such as diabetes mellitus. Diabetes mellitus may enhance the risk of adhesive capsulitis around 2-4 times than healthy people in the general population. ${ }^{23}$ In the general population, frozen shoulder is thought to have an incidence of $2 \%$, and other studies stated of $3 \%-5 \%$, while diabetic patients are 
thought to have the incidence up to $20 \% .^{4,23}$ Painful phase of the frozen shoulder which is followed by stiffness is suggesting that the initial inflammatory response has evolved into a fibrotic reaction. ${ }^{24}$ The embarking factors in the frozen shoulder is still inexpertly understood. Recent studies show that the embarking fibroblastic proliferation inside the capsule, later on, is followed by fibroblast to myofibroblast transformation. ${ }^{24}$ This is resulting in an inflammatory contracture of the shoulder which diminishes the capsular volume and significantly withstanding the movement of the glenohumeral joint. ${ }^{3,24}$

Management of frozen shoulder is still controversial and relies on the phase of the disease. Quality of life and whether the patients can handle the pain and/ or stiffness until its time of resolution are important in deciding the choice of treatment. The treatments are varying from conservative therapy until surgical measures. ${ }^{25}$ Conservative treatment choices may consist of oral non-steroidal anti-inflammatory preparations (NSAIDs), physiotherapy, etc. For symptomatic pain relief, NSAID is the choice and also it can be used in any stage of the frozen shoulder. This treatment effect for the disease progression is still poorly understood. Physiotherapy is the major choice of early and mid-stage disease. Most of the trials and studies conducted indicated the decent improvement following the role of physiotherapy. The advancement is achieved in pain scores, functionality, and range of motion. ${ }^{26-28}$ There was a study conducted by Griggs et al. showed that the majority of 77 patients who were given nonoperative treatment including physiotherapy and passive stretching were satisfied with the result. $90 \%$ of the patients satisfied following the prospective study which is controlled for over two years. ${ }^{26}$ As we know physical exercises are still the mainstay of treatment as a result of high satisfaction value.

The usage of corticosteroids has also been examined in several studies. Not only do oral corticosteroids, but intra-articular corticosteroids also demonstrate a shortterm clinical benefit. At significant improvement especially for the pain at night and quick initial recovery. However, five months of treatment showed no distinctive when compared to the control group. ${ }^{29} \mathrm{~A}$ prospective, randomized, double-blinded, placebo-controlled trial was conducted by Buchbinder showed no benefit was shown after 6 weeks following the 3 weeks of treatment with $30 \mathrm{mg}$ oral Prednisolone. ${ }^{30}$ Intra-articular steroids also showed only short-term clinical benefit as the report said no difference was demonstrated after six months besides the early clinical improvement. $^{24}$ In 2005, there was a randomized controlled trial conducted by Ryans et al., showed that a combination of intra-articular steroid injection and physiotherapy in 80 patients showed early improvement without any difference after 16 weeks. $^{31}$

\section{Overview of Manipulation under anesthesia}

MUA is still controversial among clinicians, as the indication is varied in many articles. Duration of the symptoms was used as the indication by the majority of the authors distinct from one to six months minimum duration. ${ }^{32,33}$ Before jumping to MUA other conservative treatments should be considered such as Physiotherapy, analgesics, and corticosteroid infiltrations (both subacromial and intra-articular). ${ }^{32-34}$ This intervention is done under general anesthesia only or with a supplementary brachial plexus nerve block. Lateral decubitus position can be used however the majority of the papers reported the patients positioned supine. $^{32,33,35}$

The top of the shoulder was gripped to the stabilized scapula by the supine position. ${ }^{36}$ Short lever arm was reported to be used to prevent fractures by most authors. The sequence of manipulation to reduce the complications can be used repeatedly until the maximal ROM is achieved. Usual cracking sound, snap, or the feeling of tissue breakdown of the shoulder 
was frequently notified. ${ }^{37}$ Following the MUA procedure, the patients should receive physiotherapy to maintain the shoulder joint ROM which was achieved in the procedure. The frequency of physiotherapy is often given right away after MUA. Physiotherapy sessions varied after the initial phase according to the physician and patients' condition. The physiotherapy sessions may include pool exercises, 'land-based' exercises, and also some home exercise programs. ${ }^{36,38}$

\section{MUA instead of sticking to physical therapy?}

There are many discussions among the clinicians regarding the best usage of MUA for patients with FS. There is no exact consensus from few pieces of literature to define which FS patients will benefit the most following the MUA procedure. Usually, the MUA procedure will take place following the failure of conservative treatments. The right time to do MUA is still controversial, however, it is crucial as theoretically, the sooner manipulation is done the better outcome will be achieved. ${ }^{39}$ However, MUA in early-stage may be considered as over-treatment for patients with the mild and natural progress of the disease. Furthermore, sometimes it is even considered as a contraindication if MUA is done in the early stage. On the contrary, the late intervention of MUA may lead to long complaints of persistent symptoms. ${ }^{38}$
There is also a case series that showed that there is a significant repair in all ROM following the manipulation with keeping abduction and external rotation position for the extremity compared to the manipulation only. MUA which was thought to be dangerous actually may help a lot the progress of FS as it may be the critical modality to be performed. ${ }^{40}$ However, it is important to know to combine MUA with physiotherapy programs as studies said that it may enhance the patients' ability to achieve better ROM sooner and prevent a recurrent stiffness. ${ }^{34}$

Many frozen shoulder problems may also be treated and managed in a primary care setting. Physical therapy or home exercise is still the first-line treatment for FS. Most of the cases showed that this first line of treatment is capable of resolving FS as the disease is also considered as a selflimiting disease. ${ }^{41}$ Reports added the combination of physical therapy with NSAIDs or intra-articular corticosteroid injections is evident to be more effective than those modalities of treatments alone. If MUA does not have any clearly defined indication, physical therapy has its place in every phase of the FS, starting from the freezing until the thawing phase. Physical therapy is really important even if after the patients got the surgical procedure, physical should also be applied as it may prevent recurrent shoulder stiffness. ${ }^{42,43}$

Table 1: Physical therapy alongside other conservative treatments can be applied to a patient with FS in every different stage. ${ }^{11}$

\begin{tabular}{|l|l|l|l|}
\hline & Freezing (2 - 9 months) & \multicolumn{1}{|c|}{ Frozen (4-12 months) } & \multicolumn{1}{c|}{ Thawing (5 - 26 months) } \\
\hline $\begin{array}{l}\text { Sign and } \\
\text { symptoms }\end{array}$ & $\begin{array}{l}\text { Painful shoulder worsens at night, } \\
\text { slow decreasing ROM }\end{array}$ & $\begin{array}{l}\text { Less painful shoulder followed with } \\
\text { progressive loss ROM }\end{array}$ & $\begin{array}{l}\text { The shoulder gradually improves and } \\
\text { return to wider ROM }\end{array}$ \\
\hline $\begin{array}{l}\text { Physical } \\
\text { therapy/exercise }\end{array}$ & $\bullet \quad \begin{array}{l}\text { Gentle stretching maneuver } \\
\text { Heat/ice pack }\end{array}$ & $\begin{array}{l}\text { Gentle stretching exercise } \\
\text { Isometric or static exercise } \\
\text { (strength) } \\
\text { Conservative treatments consist of patient education and oral NSAIDs or intra-articular glucocorticoid injections }\end{array}$ & $\begin{array}{l}\text { Maintaining the same exercise } \\
\text { Isometric/static exercise added with } \\
\text { resistance-based exercise }\end{array}$ \\
\hline
\end{tabular}

It is important to do the gentle stretching exercises repeatedly as the shoulder motion usually reoccurs in stiffness condition frequently. In the freezing phase, this physical therapy should be done gently without exceeding the patients' verge or comfort. ${ }^{44}$
As a clinician, it is important to choose the right methods to maintain the goal of therapy. As stated above, MUA has no right indication as it does not have any consensus yet. ${ }^{39}$ While physical therapy/ exercise is still the first-line treatment, all clinicians need to apply the physical therapy combined with other conservative therapy 
including medications in treating patients.41 Over treating patients with MUA is dangerous because it may lead to the recurrence of FS symptoms. Many aspects should be calculated in choosing treatment with MUA38. Iatrogenic complications should be avoided as it may be acquired from MUA treatment, it is important to start physical therapy first with a long term follow up. ${ }^{32,35}$ In fact, the vast majority of patients recovered well with a good satisfaction value following shoulder exercises.45 We may be considered MUA or even surgical procedures if all of the conservative treatments have failed or the patients have unbearable pain and stiffness causing so much discomfort in daily life activities. However, it is important to stick with physical therapy in any of those methods to prevent recurrent symptoms and re-intervention. In the end, we may be considered physical therapy as the core management to treat FS and also can be combined with other modalities.

\section{CONCLUSION}

Physical therapy remains the key and core choice of treatment in treating a patient with FS. Somehow, studies of MUA show quite promising results, however, we should notice that some MUA procedure complications may lead to recurrence symptoms and iatrogenic injuries. It seems that physical therapy still the most important treatment to be applied as most of the studies reported satisfaction alongside the combination of other conservative treatments. Furthermore, more studies are needed to be conducted to know the specific time and indication of the MUA procedure.

\section{Acknowledgement: None}

\section{Conflict of Interest: None}

\section{Source of Funding: None}

Ethical Approval: Not Applicable

\section{REFERENCES}

1. Duplay ES. De la periarthritis
scapulohumerale et des radieurs de l'epaulequien son la consequence. Arch Gen Med. 1872;20:513-42.

2. Codman EA. The Shoulder: Rupture of the Supraspinatus Tendon and Other Lesions In or About the Subacromial Bursa. Boston, MA: Thomas Todd Co; 1934.

3. Robinson CM, Seah KM, Chee YH, Hindle P, Murray IR. Frozen shoulder. The Journal of bone and joint surgery. British volume. 2012 Jan;94(1):1-9.

4. Shah N, Lewis M. Shoulder adhesive capsulitis: systematic review of randomised trials using multiple corticosteroid injections. Br J Gen Pract. 2007 Aug 1; 57 (541):662-7.

5. Van der Windt DA, Koes BW, de Jong BA, Bouter LM. Shoulder disorders in general practice: incidence, patient characteristics, and management. Annals of the rheumatic diseases. 1995 Dec 1;54(12):959-64.

6. Hand GC, Athanasou NA, Matthews T, Carr AJ. The pathology of frozen shoulder. The Journal of bone and joint surgery. British volume. $2007 \mathrm{Jul} ; 89$ (7):928-32.

7. Pal B, Anderson J, Dick WC, Griffiths ID. Limitation of joint mobility and shoulder capsulitis in insulin-and non-insulindependent diabetes mellitus. Rheumatology. 1986 May 1;25(2):147-51.

8. Cakir M, Samanci N, Balci N, Balci MK. Musculoskeletal manifestations in patients with thyroid disease. Clinical endocrinology. 2003 Aug;59(2):162-7.

9. Wohlgethan JR. Frozen shoulder in hyperthyroidism. Arthritis \& Rheumatism: Official Journal of the American College of Rheumatology. 1987 Aug;30(8):936-9.

10. Riley D, Lang AE, Blair RD, Birnbaum A, Reid B. Frozen shoulder and other shoulder disturbances in Parkinson's disease. Journal of Neurology, Neurosurgery \& Psychiatry. 1989 Jan 1;52(1):63-6.

11. Chan HB, Pua PY, How CH. Physical therapy in the management of frozen shoulder. Singapore medical journal. 2017 Dec;58(12):685.

12. Levine WN, Kashyap CP, Bak SF, Ahmad CS, Blaine TA, Bigliani LU. Nonoperative management of idiopathic adhesive capsulitis. Journal of shoulder and elbow surgery. 2007 Sep 1;16(5):569-73.

13. Ando A, Hamada J, Hagiwara Y, Sekiguchi T, Koide M, Itoi E. Short-term clinical results of manipulation under ultrasoundguided brachial plexus block in patients 
with idiopathic frozen shoulder and diabetic secondary frozen shoulder. The open orthopaedics journal. 2018;12:99.

14. Dodenhoff RM, Levy O, Wilson A, Copeland SA. Manipulation under anesthesia for primary frozen shoulder: effect on early recovery and return to activity. Journal of shoulder and elbow surgery. 2000 Jan 1;9(1):23-6.

15. Loew M, Heichel TO, Lehner B. Intraarticular lesions in primary frozen shoulder after manipulation under general anesthesia. Journal of shoulder and elbow surgery. 2005 Jan 1;14(1):16-21.

16. Amir-us-Saqlain H, Zubairi A, Taufiq I. Functional outcome of frozen shoulder after manipulation under anaesthesia. J Pak Med Assoc. 2007 Apr;57(4):181-5.

17. Kraal T, Visser C, Sierevelt I, Beimers L. How to treat a frozen shoulder? A survey among shoulder specialists in the Netherlands and Belgium. Acta Orthop Belg. 2016 Mar 1;82(1):78-84.

18. Zuckerman JD, Rokito A. Frozen shoulder: a consensus definition. Journal of Shoulder and Elbow Surgery. 2011 Mar 1;20(2):3225.

19. Brue S, Valentin A, Forssblad M, Werner S, Mikkelsen C, Cerulli G. Idiopathic adhesive capsulitis of the shoulder: a review. Knee Surgery, Sports Traumatology, Arthroscopy. 2007 Aug 1;15(8):1048-54.

20. Prestgaard TA. Frozen shoulder (adhesive capsulitis). Retrieved January. 2012; 10 (2012):1-27.

21. Dias R, Cutts S, Massoud S. Frozen shoulder. Bmj. 2005 Dec 15;331(7530): 1453-6.

22. Mcdonald, Christopher, M.D., Ferri's Clinical Advisor 2020, 569.e2-569.e3

23. Nagy MT, MacFarlane RJ, Yousaf Khan MW. Suppl 3: The Frozen Shoulder: Myths and Realities. The open orthopaedics journal. 2013; 7:352.

24. Hand GC, Athanasou NA, Matthews T, Carr AJ. The pathology of frozen shoulder. The Journal of bone and joint surgery. British volume. $2007 \mathrm{Jul} ; 89(7): 928-32$.

25. Dennis L, Brealey S, Rangan A, Rookmoneea M, Watson J. Managing idiopathic frozen shoulder: a survey of health professionals' current practice and research priorities. Shoulder \& Elbow. 2010 Oct;2(4):294-300.
26. Griggs SM, Ahn A, Green A. Idiopathic Adhesive Capsulitis: A Prospective Functional Outcome Study of Nonoperative Treatment. J Bone Joint Surg Am 2000; 82(10): 1398.

27. Melzer C, Hoffmann S, Wallny T, Wirth C. Frozen shoulder-treatment and results. Arch OrthopTraum Surg 1995; 114(2) : 87- 91.

28. Cleland J, Durall CJ. Physical therapy for adhesive capsulitis: systematic review. Physiotherapy 2002; 88(8): 450-7.

29. Binder AI, Bulgen DY, Hazleman BL, Tudor J, Wraight P. Frozen shoulder: an arthrographic and radionuclear scan assessment. Annals of the rheumatic diseases. 1984 Jun 1;43(3):365-9.

30. Buchbinder R, Hoving JL, Green S, Hall S, Forbes A, Nash P. Short course prednisolone for adhesive capsulitis (frozen shoulder or stiff painful shoulder): a randomised, double blind, placebo controlled trial. Annals of the rheumatic diseases. 2004 Nov 1;63(11):1460-9.

31. Ryans I, Montgomery A, Galway R, Kernohan WG, McKane R. A randomized controlled trial of intra-articular triamcinolone and/or physiotherapy in shoulder capsulitis. Rheumatology. 2005 Apr 1;44(4):529-35.

32. Placzek JD, Roubal PJ, Freeman DC, Kulig K, Nasser S, Pagett BT. Long term effectiveness of translational manipulation for adhesive capsulitis. Clinical Orthopaedics and Related Research®. 1998 Nov 1; 356:181-91.

33. Flannery O, Mullett $\mathrm{H}$, Colville J. Adhesive shoulder capsulitis: does the timing of manipulation influence outcome? Acta orthopaedicabelgica. 2007 Feb 1;73(1):21.

34. Quraishi NA, Johnston P, Bayer J, Crowe M, Chakrabarti AJ. Thawing the frozen shoulder: a randomised trial comparing manipulation under anaesthesia with hydrodilatation. The Journal of bone and joint surgery. British volume. 2007 Sep;89 (9):1197-200.

35. Jacobs LG, Smith MG, Khan SA, Smith K, Joshi M. Manipulation or intra-articular steroids in the management of adhesive capsulitis of the shoulder? A prospective randomized trial. Journal of shoulder and elbow surgery. 2009 May 1;18(3):348-53.

36. Jenkins EF, Thomas WJ, Corcoran JP, Kirubanandan R, Beynon CR, Sayers AE, Woods DA. The outcome of manipulation 
Putu Feryawan Meregawa et.al. Physical therapy and manipulation under anesthesia for patients with frozen shoulder

under general anesthesia for the management of frozen shoulder in patients with diabetes mellitus. Journal of shoulder and elbow surgery. 2012 Nov 1;21(11): 1492-8.

37. Othman A, Taylor G. Manipulation under anaesthesia for frozen shoulder. International orthopaedics. 2002 Oct 1;26 (5):268-70.

38. Vastamäki H, Vastamäki M. Motion and pain relief remain 23 years after manipulation under anesthesia for frozen shoulder. Clinical Orthopaedics and Related Research®. 2013 Apr 1;471(4):1245-50.

39. De Carli A, Vadalà A, Perugia D, Frate L, Iorio C, Fabbri M, Ferretti A. Shoulder adhesive capsulitis: manipulation and arthroscopic arthrolysis or intra-articular steroid injections? International orthopaedics. 2012 Jan 1;36(1):101-6.

40. Amir-us-Saqlain H, Zubairi A, Taufiq I. Functional outcome of frozen shoulder after manipulation under anaesthesia. J Pak Med Assoc. 2007 Apr;57(4):181-5.

41. Wong PL, Tan HC. A review on frozen shoulder. Singapore medical journal. 2010 Sep 1;51(9):694.

42. Dudkiewicz I, Oran A, Salai M, Palti R, Pritsch M. Idiopathic adhesive capsulitis: long-term results of conservative treatment. Sat. 2004;13:20.

43. Maryam M, Zahra K, Adeleh B, Morteza Y. Comparison of corticosteroid injections, physiotherapy, and combination therapy in treatment of frozen shoulder. Pakistan Journal of Medical Sciences Quarterly. 2012 May 30;28(3):648.

44. Diercks RL, Stevens M. Gentle thawing of the frozen shoulder: a prospective study of supervised neglect versus intensive physical therapy in seventy-seven patients with frozen shoulder syndrome followed up for two years. Journal of Shoulder and Elbow Surgery. 2004 Sep 1;13(5):499-502.

45. Griggs SM, Ahn A, Green A. Idiopathic adhesive capsulitis: a prospective functional outcome study of nonoperative treatment. JBJS. 2000 Oct 1;82(10):1398.

How to cite this article: Putu Feryawan Meregawa, John Nolan. Physical therapy and manipulation under anesthesia for patients with frozen shoulder. International Journal of Science \& Healthcare Research. 2022; 7(1): 104-110. DOI: https://doi.org/10.52403/ijshr. 20220118 